\title{
The perception of adolescents' inter-parental conflict and accompanied emotional security: A descriptive study
}

\author{
Fatma M. Elemary ${ }^{1,2}$, Omar Al Omari ${ }^{* 2}$, Dianne Wynaden ${ }^{3}$ \\ ${ }^{1}$ Psychiatric-Mental Health Nursing, Ain Shams University, Cairo, Egypt \\ ${ }^{2}$ Faculty of Nursing, Jerash University, Jerash, Jordan \\ ${ }^{3}$ School of Nursing and Midwifery, Faculty of Health Sciences, Curtin University, Perth, Australia
}

Received: November 15, 2015

DOI: $10.5430 /$ jnep.v6n5p84
Accepted: January 4, 2016

Online Published: January 14, 2016

URL: http://dx.doi.org/10.5430/jnep.v6n5p84

\begin{abstract}
How Egyptian adolescents respond to their parents' inter-parental conflict is relatively unexplored. This descriptive study was completed with adolescents to determine their perceptions of inter-parental conflict and the impact of this on their level of emotional security. Two hundred students from Zagazig city in Egypt aged between 13 and 17 years completed the "Children's perception of inter-parental conflict scale" and "Security in the inter-parental system scale". The findings showed that when adolescents witnessed inter-parental conflict they felt scared, sad, emotionally charged or unable to stop thinking about the conflict that they had witnessed. However, participants were unprepared to assist in trying to solve their parents' conflict. Nurses need to be aware of the negative impact that inter-parental conflict may have on adolescents in their care. Interventions should focus on the preservation of the adolescent's emotional security to prevent negative psychosocial effects occurring in the future.
\end{abstract}

Key Words: Adolescents, Perception, Inter-parental conflict, Emotional security

\section{INTRODUCTION}

Egypt is the most populous country in the Arabic region with 82.5 million inhabitants of which $25 \%$ are adolescents. ${ }^{[1]}$ Traditionally, adolescents in Egypt live with their parents and some may regularly witness inter-parental conflict. ${ }^{[2]}$ Conflict is defined as any disagreement, difference and argument about an issue that rises in family life. ${ }^{[3]}$ Inter-parental conflict is complex and multifaceted construct as it includes any differences of opinions, whether it is negative or positive between parents. ${ }^{[4,5]}$ These differences range from minor daily stresses and disagreements to severe verbal, emotional, and physical arguments. ${ }^{[6]}$ Inter-parental conflict can be destructive as the adolescent may witness their parents' dis- plays of anger and hostility or constructive conflict which depicts good role modeling and the use of problem-solving strategies and affection. ${ }^{[7]}$

The impact of inter-parental conflict on adolescents depends on whether the parents used constructive or destructive techniques to solve their conflict. ${ }^{[8]}$ There are seven dimensions that can determine the consequences of inter-parental conflict on adolescents and their parents: frequency, intensity, content, resolution, explanation given to the child, child involvement, and mode of expressing the conflict. ${ }^{[9]}$ Destructive inter-parental conflict has a detrimental effect on adolescents and may compromise areas of their normal development. It can lead to the adolescent feeling insecure in

*Correspondence: Omar Al Omari; Email: o.alomari@jpu.edu.jo; Address: Faculty of Nursing, Jerash University, Jerash, Jordan. 
the home environment and to experience subsequent socioemotional, behavioural and academic disruptions to their life. ${ }^{[4,10-14]}$ In some cases, this may place the adolescent at risk to participate in antisocial behaviours. ${ }^{[13]}$

The emotional security model provides an explanation as to why some adolescents from environments with inter-parental conflict may develop antisocial behaviours. The model postulates that parents serve as a safeguard for their adolescents and provide a sense of security and safety ${ }^{[15-17]}$ and this sense of security and safety organizes the child's emotional regulatory experiences (e.g., fear), action tendencies (e.g., withdrawal), and interpersonal appraisals. ${ }^{[18,19]}$ However, destructive inter-parental conflict disrupts this learning and may lead to the adolescent displaying negative emotions and behavioural deregulation.

In all health care setting, nurses play a pivotal role in assessing and minimizing the impact of inter-parental conflict on adolescents in their care. ${ }^{[20-24]}$ Therefore, they require knowledge and skills to be able to work effectively with the adolescent who grow up in environments where they witness inter-parental conflict and to engage appropriately with the parents to educate them about the impact of their interactions on their child. ${ }^{[20-24]}$

Worldwide, around 133 to 275 million children and adolescents witness violence in the home annually. ${ }^{[7]}$ In Egypt there are no statistics on the rate of inter-parental conflict but one info-graphic study conducted by Al-Jazeera found that $47 \%$ of married, divorced, widowed women experienced domestic violence. ${ }^{[25]}$ This paper adds to knowledge in this area by describing the Egyptian adolescents' perception of inter-parental conflict and the impact on their emotional security. The findings are transferable to other Arabic countries that share many Egyptian parents' cultures and values.

\section{MeTHODS}

Permission to conduct this descriptive study was obtained from four school principals in the city of Zagazig. Both parents and adolescents gave written informed consent to participate in the study. The "Children's perception of interparental conflict scale (CPIC)",[26] and the "Security in the inter-parental system scale (SISS)" were used for data collection along with a demographic data sheet. ${ }^{[27]}$ Permission to use the SISS and the CPIC were obtained from Davies, Forman et al. (2002) and Grych et al. (1992). [26,27]

Both questionnaires were translated to Arabic by a professional independent researcher and back translations were conducted to ensure data did not lose its richness and meaning. ${ }^{[25]}$ The translated version of the questionnaire was then checked by two Arabic/English speaking nursing professors with experience in adolescent nursing to ensure face validity of the translated questionnaires. Test-retest reliability for the Arabic version CPIC and SISS questionnaires were conducted by computing Cronbach's alpha for each questionnaire: Cronbach's alpha for CPIC were 0.863 and SISS were 0.829 , which reflects an acceptable level. ${ }^{[28]}$

\subsection{Sample}

A convenience sample of 200 adolescents from the four schools, who consented to participate completed the Arabic version of the questionnaires. The inclusion criteria were: (1) to be students from the selected schools; (2) aged between 13 and 17 years; and (3) willing to participate and commit 20 minutes to complete the two questionnaires. Completion of the questionnaires took each student approximately 20 minutes.

\subsection{Data collection}

Data collection occurred between March and April in 2014. An Independent researcher explained the study to students providing them with an information sheet and consent form.

\subsection{Measures and procedures: Questionnaires}

The "Children's perception of inter-parental conflict scale" ${ }^{[26]}$ is used to assess adolescents' perception of conflicts between their parents and uses a three point-Likert scale. The scale consists of 48 items organized into three categories with eight subscales: The first category is conflict properties, which consists of the following four sub-scales: Frequency (6 items), Intensity (7 items), Resolution (6 items), and Triangulation (8 items). The second category is threat and this consists of two sub-scales: Perceived threat (6 items) and Coping Efficacy (6 items). The last category is Self-blame which also has two sub-scales: Content (4 items), Self-blame (5 items). The adolescents responded to each item of the scale by choosing: true (2), sort of true (1), false (0) except for the items that were marked with an asterisk are reverse keyed and were scored as Grych et al.'s ${ }^{[26]}$ guidance. The credibility of the sub scales was: Conflict Properties factor (Cronbach's alpha was 0.90), Threat (Cronbach's alpha was 0.83), and for Self-Blame (Cronbach's alpha was 0.78). ${ }^{[26]}$

\subsection{Security in the Inter-parental System Scale}

Security in the inter-parental system scale comprised of 37 items developed to assess the dimensions of reactivity (9 items), behavioral dysregulation (3 items), avoidance ( 7 items), involvement (6 items), constructive family representation (4 items), destructive family representation (4 items) and conflict spill over representation (4 items). The participants rated each item based on how true it was using a 4-point continuum $(1=$ Not at all true of me, $2=$ A little true of me, 
3 = Somewhat true of me, $4=$ Very true of me). Cronbach's alpha coefficient for the scale was 0.70 which reflected an acceptable level of credibility. ${ }^{[27]}$

\section{RESULTS}

Data were analyzed using the Statistical Package for Social Sciences SPSS version 17.0. Descriptive statistics were used to summarize the demographic and inferential statistics used to establish correlation between the SISS and the CPIC and its subscales.

\subsection{Demographics}

A total of 200 students participated in the study and $75 \%$ (n $=150$ ) were males. The average age was 15.5 years and 183 $(91.5 \%)$ of the adolescents lived with both their parents (see Table 1).

Adolescents' perceptions of aspects of inter- parental conflict and accompanied emotional security were obtained using CPIC and SISS scales.

\subsection{Children's perception of inter-parental conflict scale}

The average scores were calculated for the subscales, the mean scores of the participants were: Conflict properties sub-scale $(\mu=.865 ; \mathrm{SD}=.137)$, threat sub-scale $(\mu=1.18$; $\mathrm{SD}=0.355)$ and Self-blame sub-scale $(\mu=.877 ; \mathrm{SD}=0.349)$ (see Table 2).

Table 1. Demographic characteristics of the adolescents

\begin{tabular}{lll}
\hline Items & \% & N \\
\hline Fathers' level of education & & \\
Illiterate & 1.5 & 3 \\
Primary & 11.5 & 23 \\
Secondary & 26 & 52 \\
Higher education & 45 & 90 \\
Post graduate & 16 & 32 \\
Mothers' level of education & & \\
Illiterate & 4 & 8 \\
Primary & 9.5 & 19 \\
Secondary & 35.5 & 71 \\
Higher education & 39.5 & 79 \\
Post graduate & 11.5 & 23 \\
Gender & & \\
Female & 25 & 50 \\
Male & 75 & 150 \\
Where do you live? & & \\
Parents & 91.5 & 183 \\
Single Parents & 7.5 & 15 \\
Relative & 1 & 2 \\
Total & & 200 \\
\hline
\end{tabular}

Table 2. Mean score of the adolescents' perception for the different subscales of CPIC scale

\begin{tabular}{lllll}
\hline Subscales & & Statement & Mean (SD) & Range \\
\hline Conflict properties & 19 & $.865(.137)$ & .68 \\
& Frequency & 6 & $1.048(.209)$ & 1.00 \\
& Intensity & 7 & $.746(.223)$ & .86 \\
Threat & Resolution & 6 & $.822(.185)$ & .83 \\
& & 12 & $1.18(.355)$ & 2 \\
Self-blame & Threat & 6 & $1.22(.609)$ & 1.17 \\
& Coping efficacy & 6 & $1.13(.253)$ & 1.22 \\
Triangulation & & 9 & $.877(.349)$ & 2 \\
\hline
\end{tabular}

* Researchers exclude three items because too many missing data were found.

One hundred and twelve (56.3\%) participants reported that they had never seen their parents arguing or disagreeing with each other but $164(82.4 \%)$ reported that when conflict had occurred, their parents were mean to each other. One hundred and sixty five $(82.9 \%)$ reported the main source of conflict between parents was around topics related to the house. One hundred and sixty $(80.4 \%)$ reported other reasons for their parent's conflict. For example, 128 (64.3\%) believed arguments between parents were about things related to adolescents in general and $128(64.3 \%)$ were related to things adolescents do at school. One hundred and twenty eight (64.3\%) participants believed that conflict emerged when the adolescent did something wrong. Many of the participants blamed themselves for their parents' conflict as they believed 
conflict rose as a result their fault $(62.8 \%, \mathrm{n}=125)$.

A perceived threat for witnessing conflict 193 (96.9\%) made adolescents afraid that one or both of their parents would yell at them $(82.9, \mathrm{n}=165)$ as a result they got scared and afraid about what was going to happen to them $(92.4 \%, \mathrm{n}=184)$. Furthermore, 156 of the participants $(78.3 \%)$ were worried that one of their parents would get hurt and $65.8 \%(n=131)$ were worried that their parents might get divorced.

One hundred and seventy two $(86.4 \%)$ participants believed that when their parents had a conflict they worked it out and $174(87.4 \%)$ believed their parents discussed the issue and usually came up with solution because 187 (93.9\%) of them reported that when their parents had a disagreement they discuss it quietly and 118 (59.3\%) stated their parents did not push or shove each other during an argument.

One hundred and seventy six $(88.4 \%)$ of the participants responded to the threat of parental conflict by doing something to make their parents feel better, although 186 (93.4\%) of the participants did not know what to do when their parents had argument because 181 (90.9\%) of the participants reported that when their parents argue they don't listen to them.

\subsection{Security in the inter-parental system scale}

On the SISS and its subscales, the mean scores were: SISS $(\mu=2.59 ; \mathrm{SD}=0.19)$, emotional reactivity sub-scales $(\mu=$ $2.65 ; \mathrm{SD}=0.42)$, regulation of exposure to parent conflict sub-scales $(\mu=2.66 ; \mathrm{SD}=0.18)$ and Internal representation sub-scale $(\mu=2.51 ; \mathrm{SD}=0.16)$ (see Table 3$)$.

Table 3. Mean score of the participants responses to SISS and its sub-scales

\begin{tabular}{llll}
\hline Sub scales & Statement & Mean(SD) & Rang \\
\hline Emotional reactivity & 12 & $2.65(.425)$ & 1.78 \\
Emotional reactivity & 9 & $2.97(.395)$ & 1.89 \\
Behavioral dysregulation & 3 & $2.34(.494)$ & 2 \\
Regulation of exposure to parent conflict & 13 & $2.66(.183)$ & .85 \\
Avoidance & 7 & $2.49(.198)$ & 1 \\
Involvement & 6 & $2.82(.258)$ & 1 \\
Internal representation & 12 & $2.51(.161)$ & .75 \\
Constructive family representation & 4 & $2.23(.432)$ & 1.5 \\
destructive family representation & 4 & $2.94(.414)$ & 1.75 \\
Conflict spillover representation & 4 & $2.36(.516)$ & 1.5 \\
Total & 37 & $2.59(.199)$ & .76 \\
\hline
\end{tabular}

Adolescents displayed a plethora of emotions as a result of their parents conflict; they felt scared $(\mu=2.99 ; \mathrm{SD}=.546)$, $\operatorname{sad}(\mu=2.88 ; \mathrm{SD}=0.514)$, unsafe $(\mu=2.62 ; \mathrm{SD}=.646)$ and angry $(\mu=2.60 ; \mathrm{SD}=.673)$. They were also unable to calm down $(\mu=3.03 ; \mathrm{SD}=0.388)$ and could not stop thinking about their parents problems $(\mu=3.34$; $\mathrm{SD}=0.572)$. However, they hid their feelings from their parents $(\mu=3.01$; $\mathrm{SD}=.420)$. Participants reacted negatively to their parents conflict by yelling on their parents and siblings $(\mu=2.60$; $\mathrm{SD}=0.673)$ and caused trouble to them $(\mu=2.49 ; \mathrm{SD}=$ $0.501)$.

Adolescents worried about their family's future $(\mu=3.35$; $\mathrm{SD}=0.583)$, and their parent's next move $(\mu=3.10, \mathrm{SD}=$ $0.433)$ and they did not believe their parents still loved each other $(\mu=2.38 ; \mathrm{SD}=.496)$. Although adolescents tried to preserve their emotional security they did not really know what to do $(\mu=2.91 ; \mathrm{SD}=.447)$ and they did nothing even though they, wished that they could help their parents in solv- ing their conflict $(\mu=2.59 ; \mathrm{SD}=.493)$. Some participants tried to do nice things to their parents to assist in resolving the situation $(\mu=4.99 ; \mathrm{SD}=.624)$.

\section{Discussion And CONCLUSION}

This study is the first study that has described Egyptian adolescents' emotional security and their perceptions of their parents' conflict. The findings demonstrate that when adolescents witnessed inter-parental conflict they complained of negative psychosocial consequences, which expose them to sense of insecurity that may place them at risk of internalizing and externalizing their adjustment difficulties. This finding is consistent with other research. ${ }^{[29,30]}$ Participants also reported experiencing academic and social problems. ${ }^{[5,10-14,31,32]}$ From a cognitive-contextual standpoint, intra-parental conflict served as a stressor that triggered the adolescents to cope with negative emotions that rise from witnessing this conflict. ${ }^{[33]}$ Therefore, the adolescents' perceptions of marital dispute are crucial because it affects their 
future coping style. ${ }^{[31,34]}$

Based on the cognitive theory, adolescents who witnessed their parents' conflict may display similar behavior patterns in the future. ${ }^{[8]}$ Adolescents' emotional security regarding the marital discord can be also described by using the three elements of the emotional security hypothesis. ${ }^{[35]}$ That is, when the inter-parental conflict occurs, the magnitude of the consequences on the adolescents can be determined according to three variables. Firstly, the frequent exposure to inter-parental conflict put adolescent at risk of experiencing unwanted feelings like sadness, anger, and fear. ${ }^{[35]}$ In this current study, regardless to the frequency of conflicts that participant witnessed, they reported a plethora of emotional dis-regulations which may increase their risk for adjustment problems. Secondly, adolescents gain a sense of security when they are able to minimize, control or resolve their parents conflict by either using constructive or destructive behavioural methods. ${ }^{[35]}$ Although some participants in the current study used both of the methods, the majority reported that they did not know what to do. This may also increase their risk of developing maladaptive coping strategies in future. Lastly, adolescents are able to build up and understand inter-parental conflict based on their cognitive abilities and past experiences with conflict. ${ }^{[35]}$ Adolescents who observed their parents reactions during times of conflicts and how they resolved it positively, learned necessary skills to overcome any potential conflict or challenge they may encounter in the future. This is supported by other researchers ${ }^{[36]}$ who stated that parental conflicts that are resolved positively can be beneficial to parents and their children as children may learn how to solve their own conflicts in adaptive ways with others. This view is supported by previous research of the same result. ${ }^{[8,37-41]}$

There is a need for teaching parents how to solve their conflict constructively to maintain the sense of security between the family members. Previous research found that teaching parents what to do to handle the conflict in a constructive way led to positive changes in their relationship, which in turn reflected on their children level of security and improved their adjustment to internal and external stressors. ${ }^{[42,43]}$ Nurses may organize meetings with parents to share with them experiences and skills in solving conflicts. There is also a need to teach adolescents to trust their abilities and learn when and how to interfere with their parents' conflict. This in turn will have a positive impact on participants' level of emotional security.

This preliminary study describes adolescents' perception of their inter-parental conflict from their perspective, there is a need to triangulate on their parents perspective regarding their conflict to obtain broader understanding to the phenomena under study; hence, we recommend future research to conduct a study considering both parents and their children.

The findings of this study generated new knowledge and understanding in this area of health care that is not searched in depth before in Arabic region. The findings will prepare community nurses, teachers and counsellors facilitate with knowledge that facilitate engagement with adolescents and their parents to assist them to better support both themselves and their family and to avoid any future destructive conflict. Previous research suggested that nurses have to be equipped with necessary knowledge and training to educate, support and assist parents to constructively solve their conflict so that adolescents can avoid negative consequences of their parents' conflict. $^{[44]}$

In conclusion, the common dominator between adolescents at the current study is the stress and negative emotions that adolescents displayed. Witnessing parents' conflict and experiencing such negative emotions may adversely impact on the future of the adolescents. Health care workers need to work closely with adolescents and need to address their psycho-emotional health needs in future health care policies.

\section{CONFLicts OF InTEREST Disclosure}

The authors declare that there is no conflict of interest.

\section{REFERENCES}

[1] United Nations International Children's Emergency Fund [UNICEF]. Adolescence. 2011. Available from: http://www . unicef .org/e gypt/children_151.html

[2] Tam CL, Lim SG. A study of marital conflict on measures of social support and mental health. Sunway Academic Journal. 2008; 5: 97-110.

[3] Cummings E, Davies P. Effects of marital conflict on children: recent advances and emerging themes in process-oriented research. Journal of Child Psychology and Psychiatry. 2002; 43(1): 31-63.
PMid:11848336 http://dx.doi.org/10.1111/1469-7610.00 003

[4] Kouros C, Cummings E, Davies P. Early trajectories of interparental conflict and externalizing problems as predictors of social competence in preadolescence. Development and Psychopathology. 2010; 22(03): 527-37. PMid:20576176 http://dx.doi.org/10.1017 /S0954579410000258

[5] Cummings EM, Davies PT. Marital conflict and children: An emotional security perspective: Guilford Press; 2011.

[6] Esfandyari B, Baharudin R, Nowzari L. The relationship between 
inter-parental conflicts and externalizing behaviour problems among adolescents. European Journal of Social Sciences. 2009; 12(1): 1216.

[7] Pinheiro P. World report on violence against children Geneva, Switzerland: United Nations Secretary-General's Study on Violence Against Children; 2006 [cited 2016 08, January]. Available from: http://www . unicef.org/violencestudy/reports.html

[8] Goeke-Morey M, Cummings E, Harold G, et al. Categories and continua of destructive and constructive marital conflict tactics from the perspective of US and Welsh children. Journal of Family Psychology. 2003; 17(3): 327. PMid:14562457 http://dx.doi .org/10.1037 10893-3200.17.3.327

[9] Atkinson E, Dadds M, Chipuer H, et al. Threat is a multidimensional construct: Exploring the role of children's threat appraisals in the relationship between interparental conflict and child adjustment. Journal of Abnormal Child Psychology. 2009; 37(2): 281-92. PMid:18855133 http://dx.doi.org/10.1007/s10802-008-9 275-z

[10] Rohrbaugh JB. A comprehensive guide to child custody evaluations: Mental health and legal perspectives: Springer Science \& Business Media; 2007.

[11] Paradis A, Reinherz H, Giaconia R, et al. Long-term impact of family arguments and physical violence on adult functioning at age 30 years: Findings from the Simmons Longitudinal Study. Journal of the American Academy of Child \& Adolescent Psychiatry. 2009; 48(3): 290-8. PMid:19182693 http://dx.doi.org/10.1097/CHI . Ob0 13e3181948fdd

[12] Van Doorn MD, Branje SJ, Meeus WH. Conflict resolution in parentadolescent relationships and adolescent delinquency. The Journal of Early Adolescence. 2008; 28(4): 503-27. http://dx.doi.org/10. $1177 / 0272431608317608$

[13] Wissink I, Dekovic M, Meijer A. Parenting behavior, quality of the parent-adolescent relationship, and adolescent functioning in four ethnic groups. The Journal of Early Adolescence. 2006; 26(2): 133-59. http://dx.doi.org/10.1177/0272431605285718

[14] Fallah N. Inteparental conflict and externalizing symptoms: the moderating role of positive peer relationship. Greensboro: The University of North Carolina; 2010.

[15] Davies P, Sturge-Apple M. Advances in the formulation of emotional security theory: an ethologically based perspective. Advances in child development and behavior. 2006; 35: 87-137. http: //dx.doi.org/10.1016/B978-0-12-009735-7.50008-6

[16] Waters E, Cummings EM. A secure base from which to explore close relationships. Child development. 2000; 71(1): 164-72. PMid:10836570 http://dx.doi.org/10.1111/1467-8624.00 130

[17] Bowlby J. Attachment and loss: Vol. 2. Seperation: Anxiety and anger. New York Basic books; 1973.

[18] Cummings E, Davies P. Emotional security as a regulatory process in normal development and the development of psychopathology. Development and Psychopathology. 1996; 8(01): 123-39. http: //dx.doi.org/10.1017/S0954579400007008

[19] Davies P, Harold G, Goeke-Morey M, et al. Child emotional security and interparental conflict. Monographs of the Society for Research in Child Development. 2002: i-127.

[20] Power C. Domestic Violence: What can nurses do? CPI; 2011 [cited 20165 January]. Available from: http://www.crisisprevention.com/Blog/Septembe r-2011/Domestic-Violence-What-Can-Nurses-Do

[21] Fawcett J. Contemporary Nursing Knowledge. Philadelphia, PA: Davis Company; 2000.
[22] Orloff LE. Effective advocacy for domestic violence victims: role of the nurse-midwife. Journal of nurse-midwifery. 1996; 41(6): 473-94. http://dx.doi .org/10.1016/S0091-2182(96)00062-6

[23] McClure BM. Domestic violence: the role of the health care professional. Michigan Family Review. 1996; 2(1).

[24] McDowall $\mathrm{H}$. What causes domestic abuse and how can nurses effectively support abused women? Nursing times. 2010; 106(8): 16-9. PMid:20334000

[25] Chughtai A, O'Toole M. Infographic: Violence against women in Egypt. Qatar: AlJazeera; 2015 [cited 2016 8. January]. Available from: http://www.aljazeera.com/indepth/interactive/ 2015/01/infographic-violence-women-egypt-150126150 958383.html

[26] Grych J, Seid M, Fincham F. Assessing marital conflict from the child's perspective: The children's perception of interparental conflict scale. Child development. 1992; 63(3): 558-72. http://dx.d oi.org/10.2307/1131346

[27] Davies P, Forman E, Rasi J, et al. Assessing children's emotional security in the interparental relationship: The Security in the Interparental Subsystem Scales. Child Development. 2002; 73(2): 544-62. http://dx.doi.org/10.1111/1467-8624.00423

[28] George D, Mallery M. Using SPSS for Windows step by step: a simple guide and reference. Boston, MA: Allyn y Bacon. 2003; 4.

[29] Harold G, Aitken J, Shelton K. Inter-parental conflict and children's academic attainment: a longitudinal analysis. Journal of Child Psychology and Psychiatry. 2007; 48(12): 1223-32. PMid:18093028 http://dx.doi.org/10.1111/j.1469-7610.2007.01793.x

[30] Killen M, Coplan R, editors. Social development in childhood and adolescence: a contemporary reader. United Kingdom: John Wiley \& Sons; 2011.

[31] Grych J, Fincham F, Jouriles E, et al. Interparental conflict and child adjustment: testing the mediational role of appraisals in the cognitivecontextual framework. Child Development. 2000; 71(6): 1648-61. http://dx.doi.org/10.1111/1467-8624.00255

[32] Rhoades K. Children's Responses to Interparental Conflict: A metaanalysis of their associations with child adjustment. Child Development. 2008; 79(6): 1942-56. PMid:19037959 http://dx.doi.org /10.1111/j.1467-8624.2008.01235.x

[33] Grych J, Fincham F. Marital conflict and children's adjustment: a cognitive-contextual framework. Psychological Bulletin. 1990; 108(2): 267. PMid:2236384 http://dx.doi.org/10.1037/003 3-2909.108.2.267

[34] Jouriles E, Spiller L, Stephens N, et al. Variability in adjustment of children of battered women: The role of child appraisals of interparent conflict. Cognitive Therapy and Research. 2000; 24(2): 233-49. http://dx.doi.org/10.1023/A:1005402310180

[35] Davies P, Cummings E. Marital conflict and child adjustment: an emotional security hypothesis. Psychological bulletin. 1994; 116(3): 387. PMid:7809306 http://dx.doi.org/10.1037/0033-2909. 116.3 .387

[36] Kayfitz A. Marital Conflict, Emotional Security, and Young Children's Social and Emotional Competence. Ontario, Canada: University of Windsor; 2011.

[37] Davies P, Martin M, Cicchetti D. Delineating the sequelae of destructive and constructive interparental conflict for children within an evolutionary framework. Developmental Psychology. 2012; 48(4): 939. PMid:22004336 http://dx.doi .org/10.1037/a0025899

[38] Davies P, Myers R, Cummings E, et al. Adult conflict history and children's subsequent responses to conflict: An experimental test. Journal of Family Psychology. 1999; 13(4): 610. http: //dx.doi.org/10.1037/0893-3200.13.4.610 
[39] Du Rocher Schudlich T, White C, Fleischhauer E, et al. Observed infant reactions during live interparental conflict. Journal of Marriage and Family. 2011; 73(1): 221-35. http://dx.doi .org/10.1111 /j.1741-3737.2010.00800.x

[40] Goeke-Morey M, Cummings E, Papp L. Children and marital conflict resolution: Implications for emotional security and adjustment Journal of Family Psychology. 2007; 21(4): 744. PMid:18179346 http://dx.doi.org/10.1037/0893-3200.21 .4 .744

[41] Larrosa S, Escudero V, Cummings E. Preschool children and marital conflict: A constructive view. European Journal of Developmental
Psychology. 2009; 6(2): 170-89. http://dx.doi.org/10.1080 $/ 17405620600843247$

[42] McCoy K, Cummings E, Davies P. Constructive and destructive marital conflict, emotional security and children's prosocial behavior. Journal of Child Psychology and Psychiatry. 2009; 50(3): 2709. PMid:18673403 http://dx.doi.org/10.1111/j.1469-761 $0.2008 .01945 . \mathrm{x}$

[43] Foster H, Brooks-Gunn J. Effects of physical family and community violence on child development. Social Violence. 2011: 16.

[44] Guruge S. Nurses' role in caring for women experiencing intimate partner violence in the Sri Lankan context. ISRN Nursing. 2012. 